\title{
Algo más que el tiempo. Conmemoración de los primeros cien años de la Facultad de Letras y Ciencias Humanas
}

\author{
Kathia Hanza y Julio del Valle \\ Pontificia Universidad Católica del Perú \\ https://doi.org/I0.18800/estudiosdefilosofia.201701.009
}

In memoriam de todas y todos los que han edificado nuestra casa. In memoriam de Johanna Hamann, quien acaba de partir.

Queridos amigos, ies una casualidad que las lecciones en nuestra universidad hayan comenzado con el dictado de la Estética? No sé cómo lanzar esa pregunta $y$, a la vez, evitar que suene solemne. ¿Es casual que ese grupo de personas, unidas por el simple hecho de estudiar y enseñar, haya empezado por la materia "estética"? Sí, es preciso reconocer que pudo deberse a una circunstancia casual, azarosa, el hecho de que el dictado de las clases empezase con la Estética. Si esto es así, ipor qué razón señalar, en un acto solemne, un acto que precisamente rememora 100 años después aquella circunstancia, por qué indicar tal azar, tal precariedad en sus comienzos?

Pero, ¿de qué comienzos se trata? A juzgar por el Cuaderno de registro de asistencia de los profesores, estamos ante una serie de lecciones con un ritmo pausado: por las mañanas, de I0 a II a.m. Estética; luego, francés. En esta franja matinal, unas semanas después, se abre el espectro: aparecen lecciones de Literatura-como si alguien hubiese reparado en que le sería difícil a Raymundo Morales de la Torre dictar sus lecciones sobre poesía épica, lírica y dramática, sobre la novela, entre otros temas, sin que los alumnos estén precisamente leyendo obras literarias. ilntención o casualidad? Por las tardes, a partir de las 4 o 5 p.m., y por dos horas aproximadamente, otros cursos, latín y varios de Historia. Aquí, la intención sí parece ser evidente, pues icómo compartir un saber universitario en letras sin inmiscuirse en la Historia? 


$$
\frac{19 / 7}{10 \text { de abu }}
$$

1

Gatetien, - de Is a, m a I/ a.m.

Plan dul curso

Adrenals delizas

Prancés - de II, a,m a $12 \mathrm{~m}$

elementos

- cuaho disumes

Latim, de 4 pim a 5 f.m P.C. diler

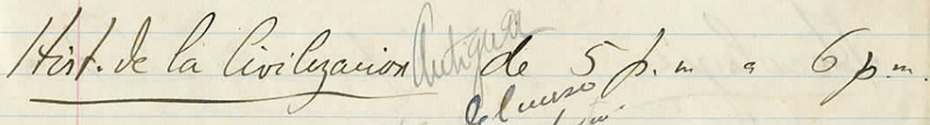
Pliaterainic do carfe

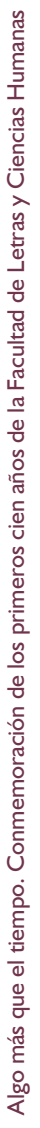

La andelcars

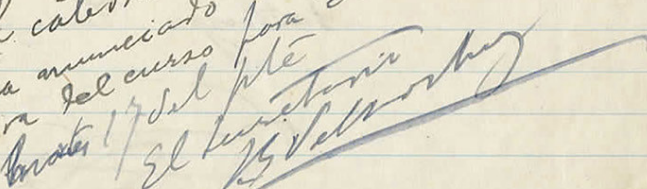

200

setwity

Cuaderno de registro de asistencia de los profesores, p. I Archivo del Instituto Riva-Agüero

143 
Dediquémosle nuestra atención a las lenguas: francés, latín y después, en setiembre, griego. Hay aquí una raíz muy profunda en los estudios universitarios modernos de corte humanístico. Ella es ciertamente muy nítida en el conjunto de cursos impartidos por los jóvenes profesores y el sacerdote francés que le dieron un comienzo a nuestra universidad. Antes, como ahora, se nos pide como requisito una segunda lengua moderna y lenguas clásicas. Ninguna otra "nativa", es decir, del país. Una raíz clásica que cien años después parece discutible, fundamentalmente porque ahora, creo yo, además de emplear otro vocabulario, hemos ampliado nuestras perspectivas. Solemos, de forma anacrónica, tildar de "discriminatoria" la omisión de otras lenguas del país, sin reparar en que así proyectamos prácticas valorativas contemporáneas a otros contextos. Por eso, antes que ingresar en el debate sobre tal anacronismo, propongo precisar otra cuestión: en vez de abordar la supuesta discriminación de la práctica que preserva el estudio de las lenguas clásicas, conviene reconocerla como una práctica integradora', una práctica propia de las humaniora ${ }^{2}$ que, como sabemos, apuntan a una tradición de muy larga data. Lo que importa en el estudio de las lenguas clásicas no es su faz contemporánea, discriminadora o anquilosada, sino su faz, también contemporánea, que recoge, reúne y renueva-idea que buscaré poner de relieve ${ }^{3}$.

Insistiré en las lenguas. A la caza de un locus classicus, podríamos deleitarnos y remontarnos, una y otra vez, a tantos magníficos autores que han hecho de las lenguas su fascinación principal -pienso, por ejemplo, en Quintus Ennius, por una metáfora gozosa: sus "tres corazones" son, nos dice, el griego, el oscano y el latín 4 . El oscano, por entonces la lengua de su país natal, Umbria, es ahora una de esas lenguas fragmentariamente atestiguadas (McDonald 20I5), como el puquina o el mochica. El latín, pues en aquella región vive Ennius de mediados del tercero a mediados del segundo siglo antes de Cristo. El griego, porque es la lengua de la gran poesía épica que él en latín emulará, desafiará, imitará o

I “Del latín integrāre, 'renovar', 'completar”’ (Real Academia Española 20I4).

2 Las humaniora, expresión abreviada del latín studia humaniora, que podría traducirse como "estudios que hacen posible una humanidad más elevada" (voz "humaniora" en: Ritter 197Iss, tomo 3, 1216-1217).

3 En la Introducción a Rorty, Schneewind y Skinne $(1990,25)$ se explica cómo se disuelven, por decirlo así, los anacronismos, pues “(...) se ha relacionado el pasado X con un contemporáneo $Y$ en lugar de hacerlo con un contemporáneo Z, lo cual habría estado mejor”.

4 "Quintus Ennius tria corda habere sese dicebat, quod loqui Graece et Osce et Latine sciret" (Aulus Gellius 2017, 17.17.I). 
cualesquiera verbos escojamos que den cuenta de esa actividad constante de aprendizaje, de estudio, de creación. Una actividad integradora que requiere algo más que tiempo, algo más que precarios u azarosos orígenes y, para el caso de las lenguas, requiere "corazón”.

¿Aventurarnos en el corazón? ¿Y si terminamos con una novelita rosa? Mejor vuelvo al griego -es un lugar solemnemente seguro. Estamos en las lecciones de nuestra facultad en 1917. Una tarde, ya en setiembre, se empieza a dictar el griego. Tiene, claro, mucho sentido incluirlo en las humaniora; pero, icómo hacerlo? En la segunda semana, leemos, lapidariamente, en el cuaderno de asistencia: "No hubo discípulos”. ¿Discípulos o estudiantes? ilniciados o descorazonados? ¿Qué pensar de ese grupo de alumnos que ya en la segunda semana de clases no aparece? ¿Casualidad o necesidad? A lo mejor, simplemente un malentendido. Pero, ipudo a alguno de ellos parecerle su primera lección de griego una especie de iniciación, un apartarse de lo ortodoxo, común, para ingresar a algo bizarro, extravagante, peculiar, en los parámetros de ahora, quizá, sectario? ¿Qué siente un joven de 17 ○ 18 años cuando descubre que tiene que aprender, nuevamente, un alfabeto? ¿Se lanza a la aventura en pos de descifrar a Homero (desafiantemente clásico: Aièn aristeúein ${ }^{5}$ ) o rememora una circunstancia no grata, la a veces tediosa disciplina de las letras? Dejemos tranquilos a los estudiantes y pensemos en el maestro. Las clases de griego continuarán, al menos hasta fin de año, no habrá ninguna otra "estampida" -el temor recurrente de profesores y decanos. El profesor podrá continuar sus clases; pero, si acaso las impartiese como teniendo la llave para descubrir un secreto misterio, no sería propiamente una actividad la que ocurriría allí, menos una actividad integradora. Sin el pálpito del corazón solo queda la repetición mecánica; también necesaria, por cierto, pero cuyo paroxismo -nítido en la siniestra expresión “ila letra con sangre entra!"- omite que, para la sangre, también está el corazón.

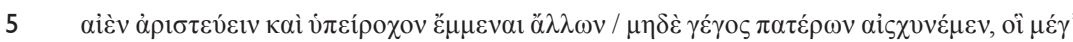

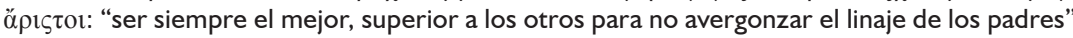
(Homero 1999, Ilíada 6.208-209). 


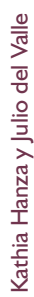

106

Airt. de la Aorigacion Antigiea-s= 6

Bliciver inde setienase Aicología $10-11$ Don.

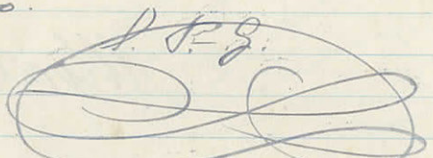

briti de la diderahur Gastettana N-12

be Pabic Dru Nem Dot. Alladurs.

Sriego

$$
\text { x. } \sqrt{5}
$$

Pbo hubs lijéfoulot.

Cuaderno de registro de asistencia de los profesores, p. 106 Archivo del Instituto Riva-Agüero

146 


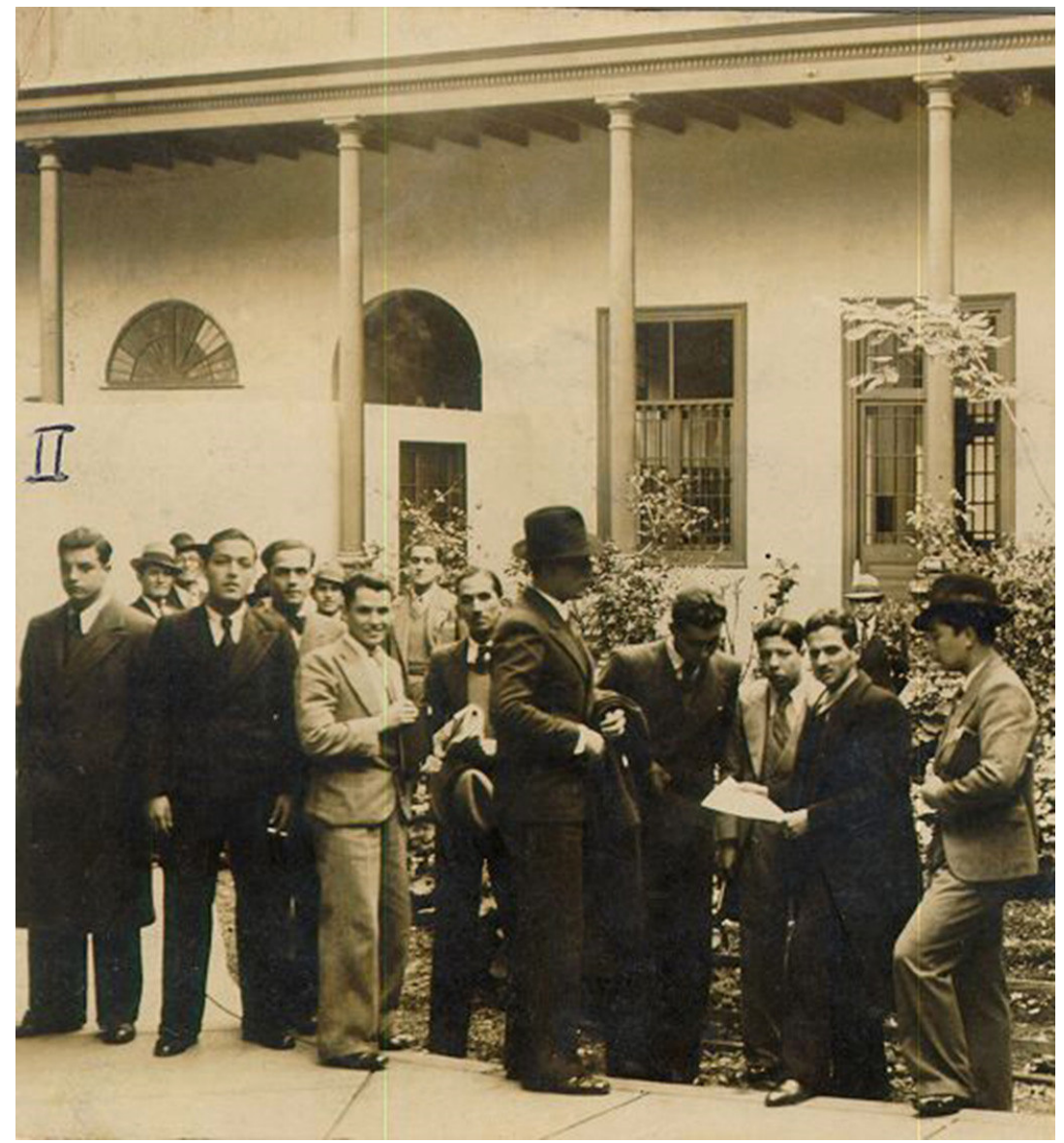

Patio de la Universidad Católica, 29 de setiembre de 1935 Archivo del Instituto Riva-Agüero 
Dejemos también tranquilas a las letras. Ellas estánya, alevosamente por mi parte, "sobredeterminadas". Volquémonos mejor a la Estética. Su nombre, en contextos universitarios, tiene fecha de nacimiento: Baumgarten dicta, en el semestre de invierno de 1742 a 1743 (en la Viadrina, Universidad de Fráncfort en el Oder), las primeras lecciones sobre Estética ${ }^{6}$. Pero solo tangencialmente me referiré a él, pues Julio, en unos minutos, les hablará sobre Baumgarten. Yo quisiera, más bien, trazar en términos muy generales

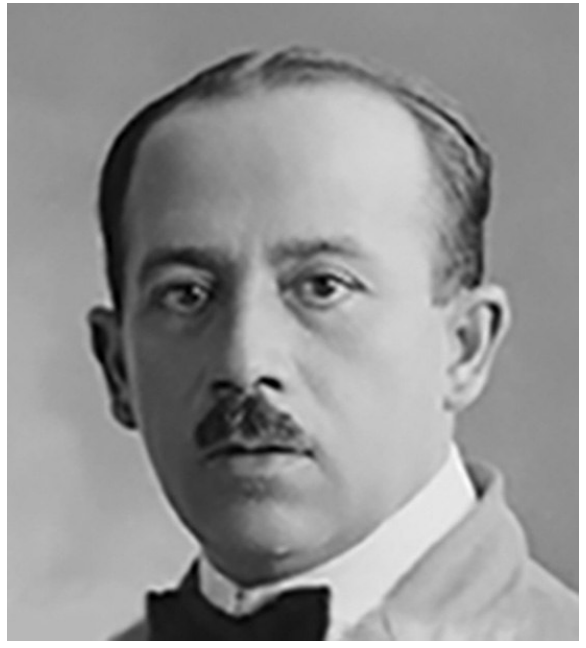

Raymundo Morales de la Torre Archivo del Instituto Riva-Agüero el trayecto que Raymundo Morales hace en ese primer curso de Estética en nuestra universidad, tal como es recogido en el Cuaderno de asistencia.

Las primeras lecciones bosquejan lo que Morales llama la "evolución general del arte" y la "evolución general de las artes plásticas". Ese interés histórico se hará palpable en la secuencia que Morales escoge. Casi una tercera parte del curso consistirá en un recorrido sobre el desarrollo histórico de las artes de la palabra: épica, lírica, drama, oratoria y novela, como ya mencioné. Al llegar a la Modernidad, con la novela, el curso cobra un giro más claramente temático: los asuntos tratados a continuación son el artista, la obra, el público, la crítica. Temas que en ese preciso momento comienzan a ser centrales y actuales: en el siglo XVIII, el siglo de Baumgarten, el siglo de la estética, el siglo de las luces. Y, de pronto, es como si coincidiese el curso de Morales con aquel acontecimiento: el surgimiento de la Estética como disciplina filosófica. En efecto, Morales opta, a continuación, por un tratamiento sistemático en las lecciones: lo bello, lo sublime, lo cómico y la armonía son los principales puntos que aborda. No solo eso; también en aquel siglo, el de la estética, los

6 Sus lecciones sirven como fuente para que publique, en 1750 , el texto no terminado de su libro principal: Aesthetica (Schwaiger 20II, 19; voz „Ästhetik“ en: Ritter I97Iss, tomo I, 555-580, en especial 555-564). 
estudios históricos cobrarán nuevos bríos y, casual o necesariamente, dirige el profesor, de forma paulatina, la atención en sus clases a determinados desarrollos históricos: la antigüedad griega, el helenismo, el renacimiento, el humanismo, el clasicismo, el romanticismo y, finalmente, el modernismo.

Hay un aspecto más de ese curso que quisiera destacar: en momentos clave, Morales trae a colación ideas, para su tiempo, especialmente novedosas y actuales. En las primeras clases trata de "la influencia de la música en las artes plásticas", patente en el siglo XIX y en las vanguardias del siglo XX. Y se ocupa también de "la estética del fierro", sin que podamos saber si su interés se debe a una crítica a la arquitectura del hierro del siglo XIX o a un elogio del art nouveau, propio de su época. Además, cierra el curso con el modernismo, la corriente literaria que en aquel tiempo despunta. Estamos, pues, ante un curso que aborda cuestiones fundamentales de la materia, integra a otras disciplinas humanísticas y considera lo que, para su tiempo, es vigente.

Considero legítimo preguntarse por qué Estética en el siglo XVIII con Baumgarten, en 1917 con Morales y, ahora, con nosotros. Hoy estamos celebrando, pero ello no me exime de, lanzada una pregunta, intentar dar una respuesta. Apelo, pues, a su paciencia para prestar atención a la raíz de la palabra estética: aísthēsis, sensación. Ese tipo de asunto humano que solo puede ocurrir gracias al cuerpo. Sobre el que Merleau-Ponty sostiene que es -y aquí la jerga filosófica puede ser hermosa- “(...) un sí mismo [soi], no por transparencia, como el pensamiento (...) sino por confusión, [;] un sí mismo que es tomado entre dos cosas, que tiene un anverso y un reverso, un pasado y un por venir" (Merleau-Ponty 2006, 14). Sea hace más de doscientos, cien años o ahora, una sola cosa podemos sacar en claro de la Estética: no puede ocurrir sin cuerpo ni tiempo. Para las pocas cosas de las que podemos obtener certezas, no está nada mal. Ahora bien, sobre ese nexo temporal, material, corporal, que se siente, pueden proponerse y hacerse -iqué duda cabe!- disparates o cosas con sentido. Entre las cosas con sentido está, creo yo, la actividad integradora de la Estética.

Su actividad reúne, no simplemente porque deba recurrir, de manera intencionada o casual, a otros campos del saber. $Y$ viceversa: cualquier campo de las humaniora sería impensable sin la Estética. Ahora bien, integrar es algo distinto a proceder como si entre las disciplinas humanísticas deba o pueda 
haber una suerte de delimitación de territorios o pretensiones de legitimidad. Integrar es, también, algo distinto a creer que haya razones para sentirnos (como "humanoides") amenazados, como si proviniese de los otros ceder a lo inerte, lo mecánico, en vez de retarnos a desplegar, con todos nuestros sentidos, una actividad. Y, por último, para integrar es irrelevante que puedan, analíticamente, separarse lo teórico (el conocimiento, la crítica) de lo práctico (la creación, la técnica, el desempeño); más bien, en ambos casos pesa un saber que no puede ocurrir sin cuerpo, quizá el rastro humano más nítidamente contingente.

Para reconocer por qué la Estética y, por supuesto, con ella, las humaniora son actividades integradoras, es preciso, sobre todo, librarse de un prejuicio en particular: suponer que la aísthēsis es una impresión, a lo sumo una reacción de un elemento que, con base en una oposición mecánica, binaria, es tomado como corporal, material. Estética es por sobre todo sentir y, por eso, una actividad. Como tal, y permítanme el juego de palabras, no se despliega con el tiempo, a la manera de una suma, sino en él. Esa es también la razón por la cual la Estética y las humaniora son siempre rabiosamente actuales. Pues no pueden menos que reconocer, para su tiempo, cómo aquel prejuicio -la suposición de que sentir sea reaccionar- distorsiona, en los tantos modos complacientes de lo contemporáneo, el núcleo del sentir. Hoy por hoy, en mi opinión, sentir se desfigura en el especular deseo narcisista que hace de quien consume la clave de toda acción humana. En efecto, para la sociedad contemporánea, pareciera que una sola cosa fuese perentoria, indispensable, primordial: complacernos. Algo negociable con el mejor postor. Pero sentir comporta una decisión, una práctica y un trabajo sobre uno mismo. Si ello es así, no veo razón alguna para que, descorazonados, hagamos prevalecer la indolencia y la indiferencia.

Ahora se despeja, espero, más claramente el sentido de la Estética y de las humaniora como actividades integradoras. No las inhibe el azar, ni se amparan en la necesidad. Ellas no pueden hacer otra cosa que volcarse a cuanto haya de humano o, si se quiere, de contingente, precario, material, aparentemente insignificante, pues de su cultivo surge nuestra humanidad. Reconocerlo no es, tampoco, figurarse una idea abstracta ni resignarse a una versión menor de lo absoluto (Marquard 1984). Por el contrario, tal cultivo es valioso pues importa a cada uno $y$, por eso, a nosotros. 
Quizás fue el azar lo que permitió a Raymundo Morales de la Torre ofrecer la primera clase de Estética un martes 10 de abril de 1917. El azar es la ocasión del corazón. Nos sitúa en lo que somos, sin la vestimenta del designio y la perspectiva. En ese punto, la ocasión perfecta para el recuerdo de lo que somos, la Estética, sin inhibición ni amparo en la necesidad, se hace cargo, hasta donde puede, de nuestra temporalidad sensible y reflexiva.

Kathia nos recuerda a Alexander Baumgarten, quien fue el primero en acuñar el término "Aesthetica" y el primero en ofrecer un curso sobre ella. Su definición la presenta así: "La Estética (o teoría de las artes liberales, gnoseología inferior, artes de los pensamientos bellos, arte del análogo de la razón) es una ciencia del conocimiento sensible" (Baumgarten 2007, Prolegomena, § I). Una definición extraña para una mente analítica, porque ensambla características, en lugar de separar y distinguir. Dice que es una ciencia. Una ciencia nueva y extraña; una disciplina joven en una universidad recién fundada. Una cátedra en manos de un profesor de 32 años, jovial, culto y sensible, hace cien años.

Con esa perspectiva empiezo y pregunto: ¿de qué manera es actual tal acontecimiento para nosotros, tal ciencia extraña?, iqué suerte de reflexiones se pudieron suscitar en la mente y el espíritu de esos nueve jóvenes matriculados esa mañana de abril de 1917 y, para nosotros, cómo puede ser incluso propicio recordar el sentido de la reflexión estética para conmemorar un centenario de actividades académicas?

Las lecciones de Baumgarten recogen y amplían sus primeras reflexiones aparecidas en las Meditationes philosophicae de nonnulis ad poema pertinentibus (1735). En esta breve obra, que es su Habiltación para la Cátedra de Filosofía, expresa sus intenciones con esta nueva disciplina, la presenta e identifica sus alcances.

La tarea es ofrecer una imagen más completa del ser humano. Una cuyo norte no esté marcado enteramente por el riguroso conocimiento de los conceptos generales que nos vinculan con un entendimiento puramente abstracto del mundo, sino una donde esta determinación conceptual, sistemática y abstracta (que él llama "lógica”) sea complementada por el desarrollo de una especial 
mirada hacia lo particular del mundo, aquella mirada desde la sensibilidad humana (que él llamará “estética”).

El recién acuñado término “Aesthetica” refierea la percepción sensible (aísthēsis), pero no se restringe a ella. La nueva disciplina aglutina en sus pretensiones teóricas, tal como está expresada en la definición antes enunciada, el rol de la cognición sensible, una teoría del razonamiento analógico, la relación entre las bellas artes (como expresión más acabada de la expresión sensible), una teoría del conocimiento (pues se trata de elaborar una nueva ciencia) y también, como hemos visto, una defensa de las artes liberales.

Se trata, si se ve con cuidado, de un matrimonio muy particular entre la sensibilidad y la inteligencia, donde ninguna tiene primacía, sino que se estimulan mutuamente; o, como decía Kant, quien nunca se casó, se trata del libre juego entre la imaginación y el entendimiento. Un matrimonio ideal, un complejo equilibrio. Se trata, de manera precisa, más académica y formal, de una osada respuesta a la vieja y fundamental pregunta filosófica por la relación entre lo uno y lo múltiple. La Filosofía ha privilegiado la unidad de lo múltiple a través del concepto; la Estética, sin dejar de lado el concepto (¿cómo podría eso ser

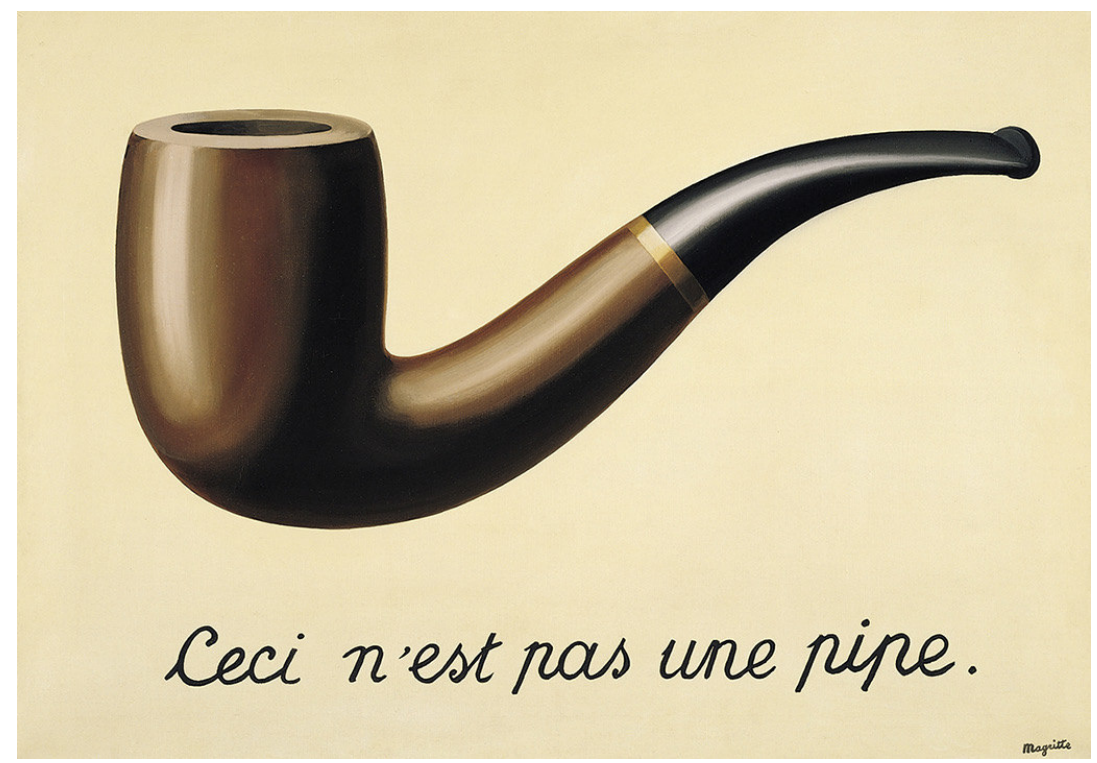

René Magritte, Ceci n'est pas une pipe (1929) 
posible?), no deja de mirar la particularidad en lo múltiple desde una sensibilidad reflexiva. ¿Cómo? La palabra clave es asociación, complementariedad, un proceder racional analógico. La representación que no se agota en la distinción.

Si no es una pipa, iqué es? "¿Acaso has medido suficientemente mil acres? / Acaso has medido suficientemente la tierra? / ¿Te has ejercitado lo suficiente para aprender a leer?", pregunta Walt Whitman $(1985,33)$. ¿Lo has hecho? ¿Te has ejercitado lo suficiente para aprender a leer el mundo que se despliega ante tus ojos? El mundo que es eso, una pipa, y mucho más; el mundo que es la representación de una pipa y que no es una pipa, porque no la podrás fumar; el mundo que te dice que le hagas y no le hagas caso a una imagen. El mundo que es mucho más que un concepto que puedes entender.

La complementación del conocimiento adquirido por las ciencias y la filosofía abstractay general se da a través de algunos recursos poéticos como la metáfora y el símbolo. Ambos expresan un tipo de verdad distinta a la de la Lógica que es llamada verdad "poética" o "estética”. La verdad lógica es descrita como una verdad universal e intensiva (pues vale para todos los miembros de una clase y respecto a ellos diferencia y divide hasta sus últimos elementos); la verdad poética es descrita como relacional y extensiva (dado que vincula al sujeto con otros particulares y en su representación ensambla; por eso es confusa, es decir, no es distinta, sino compleja). Ambos tipos de verdades se complementan: una de ellas determina los objetos desde el entendimiento y nos ofrece la perspectiva de lo general; la otra, hace significativos los objetos y nos ofrece la perspectiva desde lo particular, desde la intuición sensible. Ambas son racionales, pues se sostienen en la representación clara de algo; una de ellas es distinta, la otra compleja. Se trata de dos complementarias, aunque distintas, formas de claridad: en la primera el timón lo tiene la inteligencia discriminadora; en la segunda, una cierta inteligencia sensible asociativa.

Suficiente con la teoría. ¿Por qué puede interesar mostrar distintos tipos de claridad reflexiva? Porque el mundo es también un escenario valorativo y significativo. $Y$ las razones para defender este mundo desde la sensibilidad reflexiva eran tan válidas hace poco menos de 300 años, en la Prusia de Baumgarten y Kant, como hace 100 en la Lima de 1917, en el gobierno de Pardo, en el tercer año de matanzas de la Primera Guerra Mundial y en el año de las revoluciones rusas. Y son tan válidas hoy, en un año ya signado por las 
amenazas a las que el ser humano se expone por su desenfrenada avaricia, las devastadoras consecuencias de la inequidad en el reparto del poder y los bienes, y el sordo, ciego interés que descuida la relación con el medio ambiente; y hoy, también, en que felizmente nos congregamos para celebrar algo más que el tiempo. Las razones apuntan al corazón, al invisible lazo espiritual que une las ideas y los empeños del ser humano, especialmente en la formación de personas completas, capaces de integrar lo que piensan y lo que sienten: su cabeza y su corazón. Tanto en el siglo XVIII como ahora es claro que una visión exclusivamente categorial de lo existente es parcial e incompleta; la insuficiencia se hace más nítida cuando consideramos al ser humano.

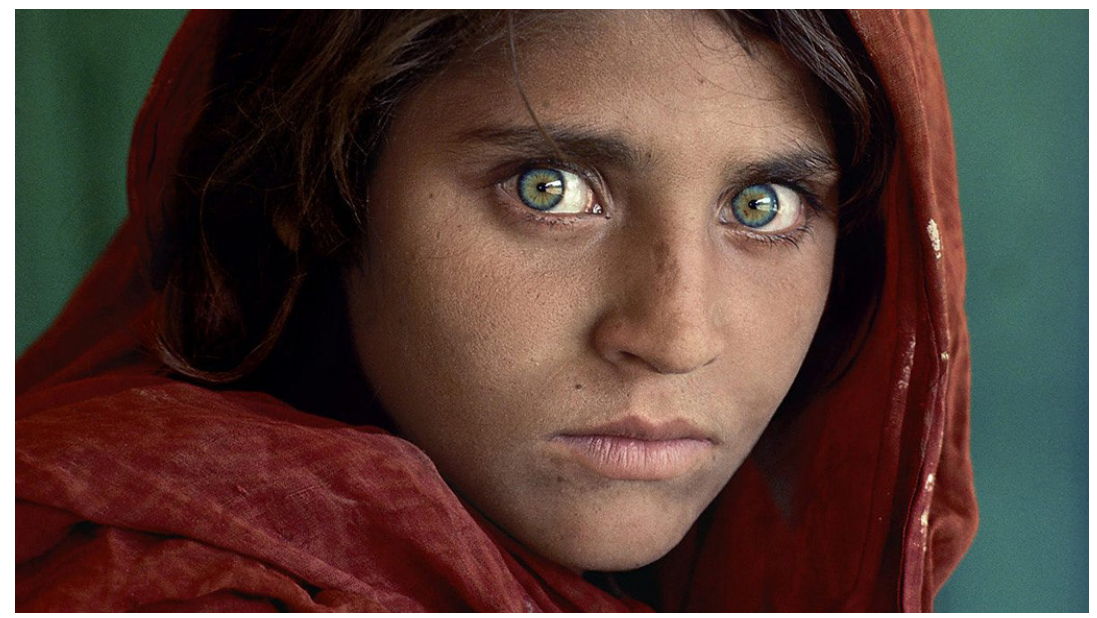

Steve McCurry, La niña afgana (1985)

La niña de la foto es, claramente, más que el registro de un rostro entre otros miles de rostros en un campamento de refugiados en el borde de Pakistán con Afganistán, es más que el nombre (Sharbat Gula), es más que un registro fotográfico. Ella, con la boca cerrada y los ojos inmensamente fijos y abiertos, me revela su mundo, su presente, su pasado y su futuro. Ella, con su mirada, me revela mi mundo: lejano en el tiempo y en el espacio, ahora, en una ciudad relativamente protegida, en una universidad relativamente privilegiada, en un país medianamente constituido. No me malentiendan: Lima no es muy segura, vivimos en una ciudad caótica, esta universidad que celebra nos cuesta un enorme trabajo cotidiano y el nuestro es un país muy precario aún. Eso me queda claro. La niña de 12 años, sin embargo, vivía en un campo de refugiados, 
no tenía casa, ni ciudad, ni país. Y su mirada lo expresa. Y la representa en una fotografía; en esa fotografía y no en los cientos de otras que Steve MacCurry y otros cientos de fotógrafos tomaron a cientos de otros niños, mujeres y hombres en los jirones de años en los que el tejido de Afganistán se desbasta.

El Fausto de Goethe es insuperable para caracterizar la insuficiencia de la labor estrictamente conceptual. Consideremos aquel conocido pasaje del Fausto de Goethe donde Mefistófeles describe el trabajo académico como un telar de conceptos: "En realidad, comparo yo la fábrica de los pensamientos con un telar, en el que a un golpe de pedal muévense mil hilos, suben y bajan las devanaderas y corren invisibles los cabos, $y$ un golpecito solo fragua miles de combinaciones, pues eso mismo deberá hacer el filósofo que allí penetra y os adoctrina: lo primero tiene que ser así, lo segundo asá, y de ahí se deriva lo tercero y luego lo cuarto; y si no existiera lo primero y lo segundo, pues no tendríamos nunca lo tercero y lo cuarto. Así doquiera cántanlo los discípulos, pero ninguno de ellos llega a ser tejedor. Quien aspira a reconocer y describir alguna cosa viva, busca ante todo desentrañarle el espíritu; luego ya tiene en su mano las partes y solo falta, ipor desgracia!, el lazo espiritual" (Goethe 2004, Parte I, vv. 1910-1939, 795). El lazo espiritual. La descripción es espléndidamente irónica y nos muestra corrosivamente la falta de vida (de espíritu, se dice allí literalmente), la sequedad vital y mecánica, mejor dicho, del trabajo académico de gabinete; frente a él, más allá de la ventana del cuarto de estudio, está una fresca tarde de verano y, con ella, la bella lozanía de los jóvenes, la ligera alegría de la calle y la frescura de lo inesperado. En la calle está la vida, mientras Fausto cruje entre rancios muebles y empolvados libros. Se trata de una oposición entre dos modelos de vida: uno que la exalta y otro que la empalidece. Tal descripción es tópica en la época (la contraposición entre el estereotipo del Logikus y del Aestheticus, la sequedad y frialdad del concepto versus la vitalidad de la sensibilidad) y es la antesala de la que se sirve Goethe para contar la historia del precio que va a pagar Fausto por devolverle vida a sus fatigados miembros.

El Fausto de Goethe contrapone como rivales a los sentidos, los placeres y las pasiones con la razón calculadora, analítica y determinante. Mefistófeles, disfrazado de profesor, busca deshacerse de la inoportuna visita de un estudiante que le pregunta por el camino del saber acerca de la ciencia y de la vida, mientras Fausto se prepara para salir al mundo con la esperanza de gozar 
de la vida. Lo que aparece de valioso en la Estética que se desarrolla desde Baumgarten es que no ofrece una imagen del ser humano sobredimensionada en alguna de sus partes, sea esta la racional o la sensible, la espiritual o la instintiva, sino que apuesta por la armonía y la complementación entre todos los diferentes aspectos que constituyen a esta criatura compleja y heterogénea que es el ser humano. Razón y corazón o, si preferimos, una suerte de lógica sensible, un delicado y resbaloso equilibrio entre inteligencia e imaginación.

Debido a la exigencia de certeza, de claridad, de determinación fundamentaly definitiva de una cierta esencia, la tradición occidental ha tendido a escindir al ser humano y ha convertido, según sea la intención determinante, la parte en el todo. Lo común a todas estas pretensiones de determinación de la esencia humana es la intención discriminadora de aquello que es lo propiamente humano. En relación con el ser humano, la consecuencia de esta pretensión discriminadora es su desgarramiento teórico; la consecuencia práctica de ello es el desplazamiento de la imagen del ser humano hacia aquella característica privilegiada y el consecuente olvido o negación de todo aquello que no va de la mano con la discriminación lograda. Así, por ejemplo, el ser humano ha sido visto, bajo la influencia platónico-cristiana, como un alma perfectible y con pretensiones de semejanza con la divinidad. Desde esta pretensión, coherentemente, se ha tendido, según los matices que cada época le otorga, a desplazar, ocultar, negar o reprimir la dimensión corporal, sensiblemente intuitiva, imaginativa o sensual del ser humano; el cuerpo y la temporalidad que somos; los afectos y emociones que nos identifican. La vitalidad en la comprensión.

Sensibilidad, significación y sentidos. Equilibrios. Estéticamente, los sentidos humanos no deben tomarse solamente como órganos del cuerpo que pueden funcionar y ser estudiados separadamente. La Estética en este caso no es una psicología de la percepción ni una fisiología de las sensaciones, sino la instancia reflexiva que se sabe en el mundo desde la sensibilidad y que exige, supone y expresa una claridad especial de reconocimiento. El concepto de verdad estética es, ciertamente, un concepto resbaloso y provocador, pero es coherente dentro del marco de presentación compensatoria estética. Puede ser, sin embargo, reemplazado por el concepto de "significatividad". No pierde relevancia, salvo en espíritus orgullosos, pues nada, creo, nos puede impedir pensar, y no solo sentir, que a través de un poema, de una obra plástica, de 
una película, de un paisaje, de manera particular, ciertamente, desde una singularidad inobjetable, se obtenga una clara, aunque peculiar conciencia del mundo o de la parte a nosotros expuesta del mundo. Nada puede escamotearnos la profunda convicción que se tiene de que, a través de la experiencia estética, nuestros sentidos entran en una feliz alerta, nuestros ojos alcanzan a ver más, nuestra mente es más lúcida y nos podemos sentir en una mayor e íntima conexión con el mundo.

Consideremos, pues, para terminar, cómo puede darse este lúcido y fértil juego reflexivo entre la imaginación y el entendimiento tomando como telón de fondo el tiempo que nos reúne; consideremos cómo dialoga la reflexión con la sensibilidad tomando en consideración el arte; sopesemos, finalmente, si al final no late un poco más aprisa nuestro corazón y si vale la pena esta consideración reflexiva de nuestra sensibilidad.

Nietzsche dio en el clavo, no una sino muchas veces: el arte permite avistar lo que nos abisma sin perder la vida o la cabeza en el intento. Suena dramático, pero no deja de ser menos cierto; tal es el sentido primero de la ficción (el arte no es la verdad de las mentiras, no hay mentira en el arte; lo que hay es ficción, una recreación analógica e imaginativa de lo existente). No es la única manera de mirar el arte, ciertamente, pero a través de ciertas obras y

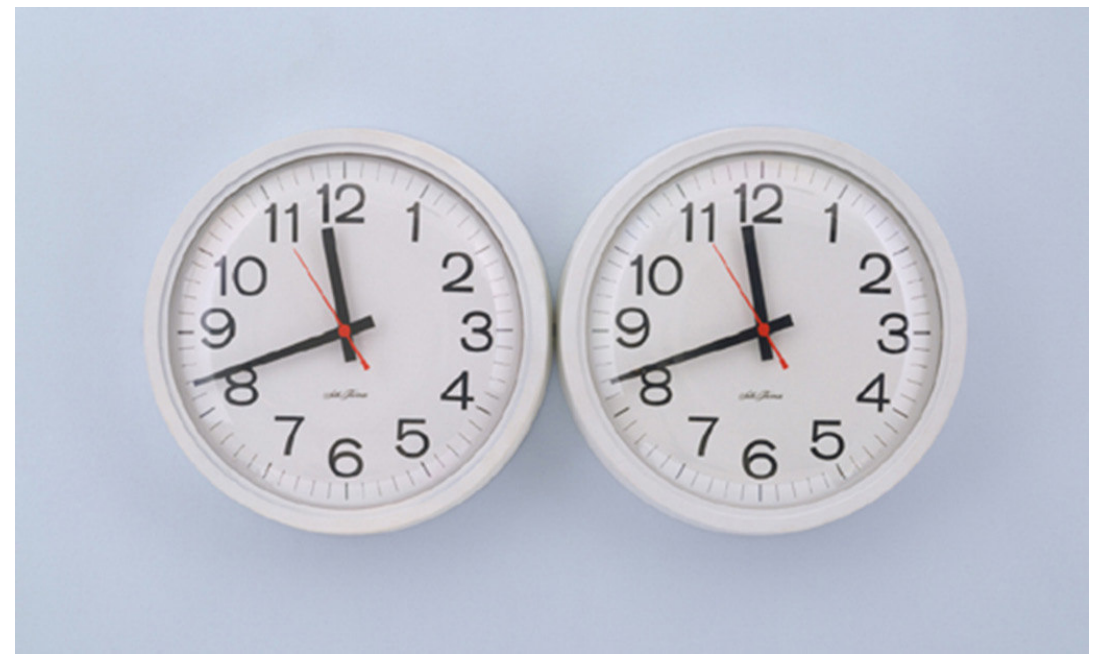

Félix González-Torres, “Untitled” (Perfect Lovers) (199I)

The Museum of Modern Art (MoMA), Nueva York, EE.UU. 
de ciertos artistas podemos enfrentar honda y honestamente aquellos surcos en la vida que preferimos sortear alegre y sanamente. Félix González-Torres (1957-1996) es uno de aquellos artistas. Lúdico, provocador, creativo y osado, nos muestra en sus obras, llamadas siempre "Untitled”, pero luego identificadas entre paréntesis, aquella mirada dirigida sin anestesia a lo inevitable. En "Untitled" (Perfect Lovers) nos muestra dos relojes idénticos, sincronizados.

En algún momento, uno de los dos relojes se detendrá. En algún momento, el otro también se detendrá. El tiempo intermedio será largo, vacío e intenso. Luego, no habrá más tiempo. Todo se habrá acabado.

Constancia del tiempo y constancia del amor. Félix González-Torres compuso la obra en ofrenda a su pareja. Memoria del amor y constancia ineludible del tiempo. Su pareja moriría pronto de sida; él, condenado también, morirá algunos años después. Con pocos elementos, dos simples relojes, construye un potente mensaje, directo, nítido, como un golpe al plexo que nos deja sin aliento y en silencio. El tiempo no requiere de adorno; las metáforas no solo son figuras literarias. Las metáforas también son verdades. El tiempo ineludiblemente está; lo mismo el amor. El único conjuro es hechizar el tiempo con amor. Lo saben los boleros, lo saben todos los que han amado y han perdido.

Nosotros, seres finitos, siempre vamos dejando algo en el camino. Nuestra parcialidad y contingencia, sin embargo, esta parte que somos, esta lúcida parte, esta llama precaria, pero constante, cargada de intencionalidad y voluntad; esta frágil y férrea llama se puede engranar en una cadena que requiere del soplo de muchas otras voces, de muchos otros cuerpos. Eso es espíritu. Un aliento vital hecho de razones y emociones. Algo, ciertamente, más que el transcurso del tiempo. Algo que une lo que somos y lo que deseamos ser, la realidad y el deseo. Entre estos polos se juega lo humano, la razón de ser y el sentido de estar aquí esta noche, cien años después, y cargados de esperanza. 


\section{Bibliografía}

Aulus Gellius, 2017. Noctes atticae, ed. John C. Rolfe. Perseus Digital Library. http:// www.perseus.tufts.edu/hopper/. Consultado 24 de marzo 2017.

Baumgarten, A.G., 2007. Aesthetica, ed. Dagmar Mirbach. Hamburgo: Meiner.

Goethe, J.W., 2004. Fausto. En: Obras completas IV, Madrid: Aguilar.

Homero, 1999. Ilíada. En: Ilíada. Odisea, ed. Carlos García Gual, trad. Emilio Crespo y José Manuel Pabón. Madrid: Espasa Calpe.

Marquard, O., 1984. Abschied vom Prinzipiellen. Stuttgart: Reclam.

McDonald, K., 2015. Oscan in Southern Italy and Sicily: Evaluating Language Contact in a Fragmentary Corpus. Cambridge University Press. https://doi.org/10.1017/ CBO978I316218457

Merleau-Ponty, M., 2006. L’œil et l’esprit (1960). París: Gallimard.

Real Academia Española, 2014. Diccionario de la lengua española. 23a ed. Madrid: España. http://dle.rae.es/?w=diccionario. Consultado 24 de marzo 2017.

Ritter, J., 197Iss. Historisches Wörterbuch der Philosophie. Darmstadt: WbG, I2 v.

Rorty, R., J.B. Schneewindy Q. Skinne, 1990. La filosofía en la historia. Barcelona: Paidós.

Schwaiger, C., 20II. Alexander Gottlieb Baumgarten, ein intellektuelles Porträt: Studien zur Metaphysik und Ethik von Kants Leitautor. Stuttgart: Frommann-Holzboog.

Whitman, Walt, 1985. Leaves of Grass (Song of Myself). En: The Portable Walt Whitman, ed. Mark van Doren. Nueva York: Penguin. 